\title{
La alfabetización informacional y digital: fundamentos pedagógicos para la enseñanza y el aprendizaje competente
}

\author{
Manuel Area*, Amador Guarro*
}

Resumen: Desde hace, al menos, una década existe una notable y continuada producción bibliográfica que defiende la necesidad de desarrollar programas educativos de "alfabetización informacional" (conocido, en el contexto español, por ALFIN), y/o de "alfabetización digital". Los autores realizan una lectura de dicho concepto desde el ámbito pedagógico, y específicamente, didáctico. En la primera parte del trabajo se sugiere la necesidad de redefinir el sentido de la alfabetización ante la omnipresencia de la cultura digital en el actual contexto de la sociedad informacional. En la segunda se aborda la conceptualización del concepto de aprendizaje competente y de las metodologías o estrategias de enseñanza que son acordes y coherentes con el desarrollo de las competencias informacionales y digitales. Se concluye con algunas sugerencias sobre el futuro del ALFIN para la formación de la ciudadanía del siglo XXI.

Palabras clave: Competencias básicas, alfabetización informacional, aprendizaje competente, competencia digital, TIC y educación.

\section{Information and digital literacy: pedagogical foundations for teaching and competent learning}

Abstract: For at least a decade there has been a substantial and continuous output of literature advocating the development of educational programs for "digital literacy" and/or "information literacy" (known in the Spanish context as ALFIN). The authors approach this concept from an educational perspective, specifically, a didactic one. They begin by suggesting the need for redefining the meaning of literacy to adjust to the omnipresence of digital culture in the current information society. There follows a conceptualization of the concept of competent learning and of the teaching methodologies or strategies that are consistent and coherent with the development of information and digital skills. The conclusion contains suggestions about the future of information literacy for citizenship training in the 21st century.

Keywords: Basic competences, information literacy, competence learning, digital competence, education and ICT.

* Universidad de La Laguna. Facultad de Educación.

Correo-e: manarea@ull.es, aguarro@ull.es

Recibido: 18-01-2012; 2. ${ }^{a}$ versión: 20-02-2012; aceptado: 23-03-2012. 


\section{Ecosistema informacional e Infoxicación: la necesidad de formar a ciudadanos competentes}

La información en sus múltiples formas (oral, textual, hipertextual, audiovisual, icónica, auditiva, multimedia...) es la materia prima de nuestra existencia moderna. Este tiempo actual del siglo xxi ha sido etiquetado como la era o sociedad informacional y/o del conocimiento (Burch, 2005), entre otras razones, porque los sujetos de las sociedades urbanas estamos inmersos en un medio ambiente o ecosistema informacional (Dini y otros, 2011) que nos inunda de forma diaria. La información es el elemento indispensable de las nuevas sociedades y las tecnologías digitales son las herramientas que permiten elaborarla, difundirla y acceder a la misma. Por ello, el desarrollo y evolución de nuestra civilización está simbióticamente vinculado con las Tecnologías de la Información y Comunicación (en adelante, TIC).

La sociedad y la cultura del siglo xxi es líquida -por utilizar una de las metáforas más potentes y difundida de los últimos años (Bauman, 2006)-, construida a través de múltiples y variadas formas simbólicas y diseminada mediante tecnologías digitales diversas. Frente a la solidez de las certezas de la cultura decimonónica -vehiculada a través de soportes físicos estables como el papel- el presente digital nos ha traído un tiempo de relativismo y mutabilidad del conocimiento, de modas efímeras de las ideas, valores y costumbres, de cambio permanente, de permisividad de las diferencias, de incertidumbre sobre el futuro mediato. En definitiva, la cultura es más compleja, multivariada y multimodal.

Asimismo, la digitalización de la información está permitiendo crear nuevas formas de codificación, representación y construcción de la cultura. Conceptos tales como los hipertextos, los hipermedia, la realidad virtual, las representaciones tridimensionales, los repositorios de archivos, los RSS, la inteligencia artificial, o la realidad aumentada... han emergido con fuerza para designar las cambios que genera la tecnología en el modo de entender y relacionarnos con la producción de información y sus formatos de representación y difusión.

Las experiencias que obtenemos de la realidad empírica tienden a solaparse y mezclarse con las experiencias que obtenemos en los espacios virtuales o ciberespacios. Por ello los ciudadanos del siglo xxi de las sociedades avanzadas y de cultura urbana vivimos simultáneamente en dos escenarios para la interacción social y cultural. El representado por nuestra realidad material, física y sensorial, y el escenario de las experiencias virtuales proporcionado por las variadas y múltiples tecnologías digitales que nos rodean (Internet, telefonía móvil, videojuegos, redes, tabletas, televisión digital, etc.). En este sentido, las TIC han alcanzado tal grado de penetración y omnipresencia en nuestra vida que sin ellas carecemos de identidad y presencia social. Tenemos una identidad reconocible y bien definida en la vida real, pero nuestra identidad como sujetos será incompleta si carecemos de visibilidad en los mundos de comunicación virtuales. Hoy en día, el 
joven o el profesional que no tiene un espacio propio y reconocible en Internet -sea en formato blog, de sitio web, de cuenta en una red social, en una lista de distribución de correo electrónico...- no existe en el ciberespacio y, en consecuencia, está aislado y sin identidad en el ecosistema de comunicación digital.

Por esta razón las TIC no sólo hemos de definirlas como herramientas o artefactos a través de los cuáles ejecutamos distintas tareas o acciones como puede ser buscar información, redactar un texto, almacenar datos, elaborar una presentación multimedia, oír música o ver una película, sino también como un espacio para la comunicación e interacción con otros individuos y grupos sociales. Las TIC son, en este sentido, uno de los principales escenarios de la socialización de un sujeto del siglo xxI y requieren ciudadanos formándose permanentemente a lo largo de la vida debido a que la cultura digital está en constante transformación tanto de sus contenidos como de sus formas. En este sentido, la obra de Carr (2010) revisa algunos de los efectos que sobre nuestra cognición y forma de procesamiento de la información está generando la Red.

Por ello la gran paradoja del tiempo actual es que a mayor cantidad de producción y difusión de información se incrementa la confusión, o si se prefiere, la ignorancia. Es lo que se conoce como "infoxicación" (Benito-Ruiz, 2009; Urbano, 2009) en el sentido de que el cúmulo y excesiva cantidad de datos genera, inevitablemente, una saturación o intoxicación informacional que provoca que muchos sujetos tengan una visión confusa, ininteligible y de densa opacidad sobre la realidad que les rodea (sea local, nacional o mundial). Por ello, a pesar de que es habitual referirnos al tiempo actual como la "sociedad del conocimiento", distintos expertos también empiezan a acuñar el concepto de "Sociedad de la ignorancia" (Mayos y Brey, 2011) en el sentido de que la acelerada transformación tecnológica y los gigantescos cambios sociales, económicos y comunicativos que conllevan generan también bolsas de analfabetos socioculturales.

Nuestra civilización actual, entre otros rasgos, se diferencia de las precedentes en que la socialización de cada individuo requiere de éste el dominio de los códigos y formas simbólicas que le permitan entender la ingente cantidad de información que recibe, y a su vez, esté en condiciones de producir y difundir información en distintos formatos. Por ello, pudiéramos también considerar que este siglo xxi, además de ser el de la sociedad de la información, es también el siglo de la formación. Nunca, en ningún periodo histórico anterior, fue tan necesaria la educación o formación de los individuos para integrarse socialmente. Sin una formación básica difícilmente un sujeto podrá ser un ciudadano autónomo y consciente de sus responsabilidades y derechos sociales. Su promoción laboral, sus valores y actitudes ante la vida, sus prácticas culturales y de ocio, sus vínculos y relaciones afectivas con los demás, su comportamiento democrático con los que le rodean y con la sociedad estará condicionado por la cantidad y calidad de la formación recibida. 


\section{En búsqueda de un nuevo concepto de alfabetización para la cultura digital}

La alfabetización es un aprendizaje instrumental indispensable para cualquier individuo porque es una condición necesaria, sine qua non, para poder obtener nuevos aprendizajes de mayor complejidad intelectual y cultural. Sin alfabetismo no es posible seguir adquiriendo nuevos aprendizajes académicos y, en consecuencia, avanzar en el sistema educativo. Asimismo el alfabetismo es una condición necesaria para la promoción e integración social, laboral, política y cultural de cada individuo. Una sociedad democrática requiere de una masa crítica de sujetos alfabetizados para que puedan ejercer y hacer uso de sus derechos como ciudadanos. No podrá haber democracia si existen bolsas de analfabetismo.

Pero la alfabetización no es un fenómeno ahistórico, sino que su concepto y práctica cambia en función del contexto y de las herramientas culturales existentes en cada periodo histórico concreto (Area y otros, 2008). Por ello la cuestión a formularnos es ¿en qué consiste ser alfabeto ante las formas culturales de la sociedad del siglo xxi? La respuesta es que un ciudadano en la sociedad multimodal e informacional del tiempo actual necesita dominar más herramientas culturales que la mera lectoescritura de textos ya que la cultura del presente es más compleja en los códigos y lenguajes así como en los soportes de almacenamiento, distribución y acceso. La información y el conocimiento, hoy en día, se expresan y representan mediante hipertextos, mediante iconos y gráficos, mediante imágenes en movimiento, mediante sonidos, mediante formatos expresivos tridimensionales. Hasta hace pocos años ser alfabeto era dominar los procedimientos de acceso a la cultura impresa, saber manejarse ante la simbología y la gramática alfanumérica, poseer las competencias de la lectoescritura. Hoy ser alfabeto es todo eso, y además, requiere ser competente en el uso inteligente de las tecnologías y de las nuevas formas culturales que las acompañan: buscar información en la WWW, participar en foros y redes virtuales, escribir en blogs y wikis, colaborar y trabajar en entornos digitales, emplear los recursos de la Web 2.0, comunicarse mediante SMS o email, etcétera.

En la cultura multimodal del siglo xxi en la que la información está en todas partes fluyendo constantemente, una persona alfabetizada debiera dominar todos los códigos, formas expresivas de cada uno de los lenguajes de representación vigentes (el textual, el audiovisual y el digital), así como poseer las competencias para seleccionar la información, analizarla y transformarla en conocimiento.

Actualmente muchos autores hablan de redefinir el concepto tradicional de alfabetización sugiriendo que el objeto de la misma debiera ser formar a los niños, jóvenes y adultos para que puedan realizar un uso culto, crítico e inteligente de la información que se vehicula a través de las múltiples herramientas y redes de naturaleza digital. En este sentido, distintos expertos, instituciones, centros universitarios, grupos de investigación y asociaciones internacionales han abor- 
dado reiteradamente, en esta última década, el problema de la formación, alfabetización o educación ante la información que se ha traducido en propuestas conceptuales como las denominadas "alfabetización en información", "alfabetización digital", "alfabetización tecnológica", "alfabetizaciones múltiples" "educación en medios" o "educación mediática" (Gutiérrez, 2010).

Existen distintas miradas o perspectivas vinculadas, lógicamente, con el ámbito o campo académico específico desde el que se formulan las propuestas. Así, asociaciones o entidades profesionales bibliotecarias como la IFLA, ALA, CILIP o REBIUN o vinculadas con departamentos y grupos de investigación universitaria del área de la documentación y archivística han generado numerosos documentos, informes y estudios en torno a la conceptualización, análisis y programas de formación sobre la denominada alfabetización o competencia informacional que, en nuestro país, ha adoptado el término de ALFIN (Bawden, 2002; Marzal, 2009, 2010; Pinto y otros, 2011 por citar algunos de los numerosos documentos académicos existentes) ${ }^{1}$.

Por otro lado, también existe una relevante tradición de estudio procedente del campo de la comunicación y/o ciencias de la información vinculadas preferentemente con las facultades y departamentos interesadas en el estudio de los medios de comunicación de masas que han propuesto conceptos como el de «educación mediática" o "en medios" que no se diferencia excesivamente del de ALFIN, aunque tiene, lógicamente matices diferenciadores ${ }^{2}$. Esta propuesta de alfabetización o educación en medios es una evolución de la antigua «educación audiovisual" que tuvo hace dos décadas una amplia difusión en los ámbitos escolares de nuestro país. Actualmente, la "educación mediática" ha tenido un impulso relevante ya que el Parlamento Europeo, en diciembre de 2009, ha aprobado una normativa que insta a los gobiernos nacionales a incorporar al curriculum escolar una materia denominada "educación mediática o en medios". Entre otros textos representativos de este enfoque podríamos citar a Kaplun (1989), Masterman (1993), y en el contexto español a Aparici (1996, 2005), Aguaded (2001, 2011), Ferrés y Piscitteli (2012) muchos de los cuales también proceden del ámbito pedagógico. Asimismo las últimas tendencias caminan hacia una cierta yuxtaposición o integración de estos distintos enfoques como es el concepto de MIL (Media and Information Literacy) propiciado recientemente por la $\mathrm{UNESCO}^{3}$.

1 Véase también el Foro Red Alfabetización Informacional http://www.alfared.org/ auspiciado por el Ministerio de Educación, Cultura y Deporte del Gobierno de España

2 Véase el monográfico de la revista Comunicar sobre políticas internacionales en Educación en Medios (Frau-Meigs y Torrent, 2009). En dicha revista pueden encontrarse más trabajos sobre "educación mediática”. http://www.grupocomunicar.com/index.php?contenido=revista. Asimismo en octubre 2011 celebró en Segovia el I Congreso de Educación Mediática y competencia digital donde pueden encontrarse distintos trabajos sobre esta temática http://www.educacionmediatica.es/

3 Véase el sitio web de la UNESCO sobre Media and Information Literacy: http://www.unesco.org/new/en/communication-and-information/capacity-building-tools/media-and-information-literacy/ 
Por otra parte, es necesario destacar que desde corrientes o ámbitos más pedagógicos también viene produciéndose bibliografía especializada sobre la alfabetización que, recogiendo por una parte, la tradición representada por el enfoque liberador y dialógico de Freire, el enfoque de formación democrática del ciudadano de Dewey, y, por otra, las aportaciones de la educación mediática crítica están pretendiendo elaborar una teoría de la alfabetización para la cultura digital. Entre las mismas figuran propuestas como el concepto de "multialfabetización" (Cope y Kalantzis, 2009), y de "nuevas alfabetizaciones" (Lankshear y Knobel, 2009).

En el contexto de nuestro país psicólogos como Coll (2005) sugieren que, en el contexto de la sociedad de la información, debe ampliarse el concepto de alfabetización letrada hacia "el dominio funcional de los conocimientos y las habilidades necesarias para manejar y manejarse con la tecnología, las imágenes fijas y en movimiento, la información, etc." Indica que la lectura de textos en Internet requiere habilidades y competencias diferenciadas de las tradicionales en la lectoescritura. Bautista (2007), apoyándose en las aportaciones de Kellner (2004) propone que una alfabetización tecnológica multimodal debe proporcionar el conocimiento de los lenguajes, así como los medios necesarios para el análisis y la producción de mensajes a través de herramientas digitales. Por su parte Area (2005, 2010), Area y otros (2008), Area y Pessoa (2012) ha planteado reiteradamente la necesidad de desarrollar alfabetizaciones múltiples para la formación de ciudadanos cultos y democráticos de la sociedad del siglo xxi.

Los textos referidos, aunque abordan esta cuestión con enfoques y apoyaturas teóricas diferentes, también coinciden en que la alfabetización (o desarrollo de competencias, tal como la refieren Monereo y colaboradores $(2005)^{4}$ debe plantearse como un proceso de aprendizaje que debe ir construyendo cada alumno, bien individualmente o en grupo, a través del uso de distintos tipos de medios y tecnologías de la información y comunicación. De este modo la tecnología no sólo se concibe como un recurso de trabajo o material de apoyo en las tareas docentes, sino también como un espacio o entorno sobre el cual el alumnado tiene que aprender a resolver situaciones problemáticas.

En definitiva, lo destacable es que existe consenso en que la alfabetización hoy en día es un proceso más complejo que la mera capacitación para saber manejar el hardware y el software digital y que la meta alfabetizadora debe ser formar al ciudadano ante los nuevos códigos y formas comunicativas de la cultura digital (Gutiérrez, 2003). Este nuevo concepto de alfabetización, en consecuencia, focaliza su atención en la adquisición y dominio de competencias centradas en el uso de la información y de la comunicación, y no tanto, en las habilidades de utilización de la tecnología.

4 En este sentido Monereo (2005) identifica cuatro grandes tipos de competencias para el uso de Internet que son: Competencias para buscar información y aprender a aprender, competencias para aprender a comunicarse; competencias para aprender a colaborar; y competencias para aprender a participar en la vida pública.

Rev. Esp. Doc. Cient., N. ${ }^{\circ}$ Monográfico, 46-74, 2012. ISSN: 0210-0614. doi: 10.3989/redc.2012.mono.977 
Este es el eje clave del nuevo enfoque alfabetizador: formar sujetos competentes en información y comunicación. Este planteamiento es coherente con la tendencia actual en la mayor parte de los países europeos y de otros países avanzados donde se camina hacia la construcción de currículos (tanto escolares como universitarios) basados en competencias del aprendizaje del ciudadano. En este sentido, la LOE (Ley Orgánica de Educación) española, ha legitimado y oficializado por primera vez una competencia formativa que recoge muchos de los enunciados, planteamientos y objetivos de la alfabetización digital e informacional. Es la competencia TICD - Tratamiento de la Información y Competencia Digital-, es un logro y avance importante ya que por vez primera el curriculum escolar español ha legitimado la necesidad de la alfabetización o formación para integrarse y usar la tecnología y cultura digital.

\section{¿A qué nos referimos cuando hablamos de competencias?}

Llegados a este punto hemos de plantearnos ¿a qué nos referimos cuando hablamos de competencias? El concepto de competencia es muy ambiguo y, además, incluye distintos tipos, lo que requiere una aclaración desde el principio y establecer el sentido que le vamos a dar en este artículo. Como quiera que uno de los orígenes más influyentes de las competencias proviene del ámbito anglosajón y del mundo profesional, seguramente la ambigüedad se inició al traducir al castellano los términos competency y competence como conceptos sinónimos, cuando los anglosajones le adjudican al primero el sentido de una cualidad concreta de una persona, y al segundo el de una cualidad genérica que no puede especificarse. Y la cosa se complica aún más al equiparar competencia con una determinado tipo de actuación (performance), más propia del término competency. De tal manera, que la competencia se asimila al comportamiento o la conducta que manifiesta quien es competente en algo, y no tanto a su significado intrínseco. Es cierto que la competencia no se puede separar de las acciones que implica su posesión, pero no es lo mismo una cosa y la otra, especialmente desde el punto de vista educativo.

También hay polémica en torno al estatus cognitivo de las competencias. Westera (2001) señala que tradicionalmente, desde una perspectiva teórica, las competencias "se conciben como una estructura cognitiva que facilita conductas específicas. Desde una perspectiva operacional, las competencias parecen cubrir un amplio rango de habilidades y conductas de orden superior que representan la habilidad para enfrentarse a situaciones complejas e impredecibles; esta definición operacional incluye conocimiento, habilidades, actitudes, pensamiento estratégico y metacognitivo, y presupone una toma de decisión consciente e intencional" (p. 80). Sin embargo, "desde el punto de vista de la investigación, las competencias constituyen una subcategoría de las habilidades cognitivas; la 
idea de 'competencia' como una categoría diferente de las 'habilidades cognitivas' es insostenible» (p. 86).

Pero para avanzar en esta discusión, especialmente desde el punto de vista educativo, y reiterando toda esa ambigüedad, nos referimos a las competencias adoptando el punto de vista y la definición que propone el Proyecto DeSeCo cuando afirma que "Vista desde fuera una competencia puede ser definida como la habilidad que permite superar las demandas sociales o individuales, desarrollar una actividad, o una tarea. Vista desde dentro, cada competencia es construida como una combinación de habilidades prácticas y cognitivas, conocimientos, motivación, valores, actitudes, emociones y otros componentes conductuales y sociales que hacen posible la realización de una determinada acción". (OCDE, 2002: 8)

O también puede ser adecuada la propuesta, aún más completa si cabe, de Tobón (2001, 2002, 2005), quien propone desde el enfoque complejo la siguiente concepción de las competencias: «Procesos complejos de desempeño con idoneidad en determinados contextos, integrando diferentes saberes (saber ser, saber hacer, saber conocer y saber convivir), para realizar actividades y/o resolver problemas con sentido de reto, motivación, flexibilidad, creatividad, comprensión y emprendimiento, dentro de una perspectiva de procesamiento metacognitivo, mejoramiento continuo y compromiso ético, con la meta de contribuir al desarrollo personal, la construcción y afianzamiento del tejido social, la búsqueda continua del desarrollo económico-empresarial sostenible, y el cuidado y protección del ambiente y de las especies vivas" (Tobón, 2007: 17).

Sin embargo, los problemas no se acaban aquí. En ambas definiciones se habla de un conjunto de elementos ("combinación de habilidades prácticas y cognitivas, conocimientos, motivación, valores, actitudes, emociones y otros componentes conductuales y sociales que hacen posible la realización de una determinada acción" o de "integración de diferentes saberes"), pero ¿qué relación existe entre cada uno de esos componentes?

Por otro lado, se habla de distintos tipos de competencias. Los más utilizados son los que se refieren a competencias ocupacionales, laborales o profesionales y académicas, aunque en este trabajo sólo nos referiremos a estas últimas. Pero dentro de esta categoría, se habla de "competencias básicas", en la enseñanza no universitaria, y de "competencias transversales o genéricas" y de "competencias específicas" de cada titulación, en la enseñanza universitaria. Y estas últimas se asemejan mucho a las competencias profesionales. En este artículo nos referiremos a las competencias básicas y a las genéricas.

Una vez establecido el sentido y el tipo de competencias a los que nos referimos, vamos a profundizar en las dos ideas que a nuestro juicio merecen destacarse del discurso competencial. La primera tiene que ver con la relación entre las competencias y el aprendizaje; la segunda, con las ideas fuerza que se derivan de las competencias, tal y como aquí las concebimos, y que debemos considerar para construir los procesos para su enseñanza y su aprendizaje. 


\section{Competencias y aprendizaje}

Las competencias representan unos espacios de aprendizajes muy ricos y significativos, pero -al mismo tiempo- muy complejos y a un nivel muy elevado. Frente a la posibilidad y a la frecuencia de enseñar aisladamente (y, en esa medida, con poca o nula significatividad) los contenidos, las competencias exigen esos espacios, que implican la integración de muchos tipos de contenidos, capacidades, habilidades, emociones, etcétera.

Cualquiera de las definiciones de competencia básica planteadas por las instituciones u organismos que han lanzado la propuesta para que se incluyan en los currículos básicos, inciden en este aspecto. La ya mencionada del Proyecto DeSeCo (OCDE, 2002), subraya claramente esta idea. Por su parte, la Comisión Europea señala que "Las competencias clave representan un paquete multifuncional y transferible de conocimientos, destrezas y actitudes que todos los individuos necesitan para su realización y desarrollo personal, inclusión y empleo (Comisión Europea. Grupo de Trabajo B, 2004:7).

Del mismo modo, el MEC indica que "El desarrollo de las competencias básicas debe permitir a los estudiantes: integrar sus aprendizajes, poniéndolos en relación con distintos tipos de contenidos, utilizar esos contenidos de manera efectiva cuando resulten necesarios y aplicarlos en diferentes situaciones y contextos"s.

Para explicar mejor lo que decimos al afirmar que las competencias suponen aprendizajes muy complejos y de muy alto nivel, hemos construido una tabla a partir de la taxonomía de contenidos que propone la teoría de la elaboración de la enseñanza (y que popularizó la LOGSE en su día mediante una versión muy sui generis), así como de las taxonomías de Merrill $(1971,1973,1977)$ y Romiszowski (1981) sobre capacidades y niveles de aprendizaje (tabla I).

\section{TABLA I}

Relación entre niveles de aprendizaje y capacidades

\begin{tabular}{l|l|l}
\hline Niveles de aprendizaje & \multicolumn{1}{|c}{ Capacidades } & \multicolumn{1}{c}{ Contenidos } \\
\hline Descubrimiento & Solución de problemas & $\begin{array}{l}\text { Combinación de todo tipo de conte- } \\
\text { nidos, especialmente principios y con- } \\
\text { ceptos }\end{array}$ \\
\hline Uso o aplicación & Análisis y clasificación & $\begin{array}{l}\text { Conceptos, procedimiento y princi- } \\
\text { pios }\end{array}$ \\
\hline Recuerdo & Conocimiento o recuerdo & $\begin{array}{l}\text { Hechos, conceptos, procedimientos y } \\
\text { principios aislados }\end{array}$ \\
\hline
\end{tabular}

5 Real Decreto $1631 / 2006$, de 29 de diciembre, por el que se establecen las enseñanzas mínimas correspondientes a la Educación Secundaria Obligatoria, Anexo 1. 
Desde un punto de vista cognitivo, las competencias se situarían en los niveles de aprendizaje de "uso o aplicación" y de "descubrimiento", lo que implica que en relación con las capacidades cognitivas se movilizan especialmente las de análisis y clasificación, por un lado, y la de solución de problemas, por otro. Es decir, las capacidades más complejas. Pero también suponen los niveles de aprendizaje más elevados. Si a todo ello añadimos que las competencias se construyen también mediante "... motivación, valores, actitudes, emociones y otros componentes conductuales y sociales" (OCDE, 2002), como hemos señalado, nos encontramos ante una propuesta de aprendizaje de una naturaleza muy compleja debido, asimismo, a la cantidad y variedad de elementos que se movilizan. Tantos como exige el aprendizaje y las actuaciones humanas en la vida cotidiana y a lo largo de toda la vida.

Todo ello, también se puede argumentar desde el punto de vista de la relación de las competencias con el "pensamiento del orden superior". Marzano (1998 y 2000) señala las destrezas que implica el pensamiento de orden superior: análisis, utilización del conocimiento, metacognición y "pensar con información".

El análisis consiste en comparar, clasificar, analizar el error, generalizar y especificar. Al participar en estos procesos, los alumnos pueden utilizar lo que están aprendiendo, para crear nuevos significados y construir conocimiento e inventar maneras de usar, en nuevas situaciones, lo aprendido. Otra forma de entender el análisis es el pensamiento crítico, es decir, cuando las personas determinan la validez y el valor de una información. Finalmente, otro tipo de análisis es la argumentación, que consiste en la presentación de afirmaciones y evidencias para convencer a otros de un punto de vista. Utilizar el conocimiento implica, a su vez, los procesos de toma de decisiones, resolución de problemas, indagación experimental e investigación. La metacognición se refiere al proceso mental que controla y regula cómo piensan las personas. Los alumnos que son metacognitivamente conscientes, son capaces de describir cómo toman decisiones y de ajustar las estrategias que utilizan, cuando estas no resultan exitosas. La utilización de información es más que añadir números y llevar a cabo análisis estadísticos. Requiere pensamiento lógico, creatividad, colaboración y comunicación. Los alumnos deben aprender a pensar responsablemente con toda clase de datos para tomar buenas decisiones en sus vidas y para participar de lleno en debates sobre los problemas políticos, sociales y ambientales de la vida contemporánea.

Las competencias, y el aprendizaje que suponen (en adelante "aprendizaje competente $^{6}$ ), son una buena oportunidad para desarrollar el pensamiento de

${ }^{6}$ Aunque tiene que ver con la tradición del aprendizaje significativo, con los niveles de aprendizaje señalados, con el pensamiento de orden superior (que incluye el pensamiento crítico), sugerimos denominarlo "aprendizaje competente" para enfatizar su vinculación con las competencias, aunque no pretendemos introducir ninguna categoría teórica, más bien una etiqueta que nos permita concretar mejor, y en el contexto de la construcción curricular, el tipo de aprendizaje al que nos referimos. 
orden superior en la escuela porque se construyen sobre (y exigen) esos procesos (análisis, utilización del conocimiento, metacognición, etc.), siempre y cuando se enseñen mediante las metodologías adecuadas.

Otro argumento que comparte las características ya señaladas del aprendizaje competente, y, añade una nueva perspectiva de análisis y valoración, tiene que ver con la relación entre las competencias y el conocimiento o pensamiento complejo.

Es cierto que las ideas de la complejidad, a pesar de que ya tienen un amplio recorrido desde que Edgar Morin las formulara7, no gozan aún del reconocimiento académico, científico y político que merecen, quizás porque suponen una ruptura con el paradigma de racionalidad hegemónico, que en términos khunianos podríamos denominar "ciencia normal". Las dificultades para el surgimiento de nuevos paradigmas ya han sido ampliamente estudiados (Khun, Kitchner, Machamer, etc.), y en este caso la ruptura es muy importante porque "las ciencias de la complejidad redefinen de raíz las relaciones mismas entre las ciencias y la filosofía, así como las ciencias entre sí, y por consiguiente, entre ciencia y sociedad" (Maldonado, 2003: 142). Esta ruptura, no obstante, se está acelerando con el desarrollo de la sociedad de la información y de la comunicación, y en la sociedad ya se admite cada vez con mayor naturalidad. La ciencia ya no se entiende únicamente como "descripción de las leyes naturales y explicación de los fenómenos, sino que conlleva la creación y la modificación de la naturaleza, y por tanto da un nuevo lugar al protagonismo humano. Uno en el cual la producción del conocimiento no es una cosa y la ética otra" (Aguerrondo, 2009: 4).

Como Elmore (1990) ya señalara hay que reinventar un nuevo modelo educativo que avance en la respuesta a preguntas tales como ¿qué es aprender, qué es enseñar y qué es conocimiento válido en la nueva sociedad? Lo que implica definir los resultados de ese aprendizaje y cómo se organiza en la nueva sociedad la relación entre el aprendizaje (¿cómo y dónde se aprende hoy?) y el conocimiento (¿qué conocimiento se debe distribuir? ¿Con qué profundidad?)

En este sentido, Aguerrondo (2009) plantea dos modelos de conocimiento (tabla II).

7 Desde la publicación de "Introducción a una política del hombre", en 1965, y sobre todo "El método", en 1977, hasta la formulación específica en "Introducción al pensamiento complejo" en 1990. 
TABLA II

Modelos de conocimiento

\begin{tabular}{l|l}
\hline \multicolumn{1}{c|}{ Paradigma tradicional } & \multicolumn{1}{c}{ Paradigma del tercer milenio } \\
\hline Su objetivo es desarrollar teoría. & $\begin{array}{l}\text { Su objetivo es resolver problemas (usando } \\
\text { teoría). }\end{array}$ \\
\hline $\begin{array}{l}\text { El nuevo conocimiento revierte en la comu- } \\
\text { nidad científica. }\end{array}$ & $\begin{array}{l}\text { El nuevo conocimiento revierte en la socie- } \\
\text { dad. }\end{array}$ \\
\hline $\begin{array}{l}\text { Enfoca los problemas de la realidad seg- } \\
\text { mentándolos. }\end{array}$ & $\begin{array}{l}\text { Enfoca los problemas desde la necesidad de } \\
\text { su resolución, mezclando disciplinas. }\end{array}$ \\
\hline No se compromete con la acción. & Se compromete con la acción. \\
\hline $\begin{array}{l}\text { El criterio de verificación es la lógica de la } \\
\text { experimentación (¿explica el problema?). }\end{array}$ & $\begin{array}{l}\text { El criterio de verificación es la lógica de la } \\
\text { efectividad (¿resuelve el problema?). }\end{array}$ \\
\hline
\end{tabular}

Estos modelos de conocimiento implican, a su vez, modelos de pensamiento (tabla III).

TABLA III

Modelos de pensamiento

\begin{tabular}{l|l}
\hline \multicolumn{1}{c|}{$\begin{array}{c}\text { Paradigma tradicional } \\
\text { Pensamiento lógico }\end{array}$} & \multicolumn{1}{c}{$\begin{array}{c}\text { Paradigma del tercer milenio } \\
\text { Pensamiento tecnológico }\end{array}$} \\
\hline - De la construcción de teoría. & $\bullet$ A la resolución de problemas. \\
\hline - De operaciones de pensamiento. & $\bullet$ A la capacidad de actuar sobre la realidad. \\
\hline - Operaciones de pensamiento: & $\bullet$ Además de las operaciones de pensamiento: \\
- Observar. & - Competencias de acción. \\
- Describir. & - Encontrar un problema (definirlo). \\
- Comparar. & - Diagnosticarlo (explicarlo). \\
- Razonar. & - Idear la solución. \\
& - Resolvero. \\
\hline
\end{tabular}

Lo que implica que "las propuestas de enseñanza y aprendizaje en el marco de la sociedad del conocimiento deberán integrar un sistema educativo cuyo objetivo sean las operaciones de pensamiento, pero no en el marco del pensamiento lógico tradicional, sino dentro de un modelo donde las operaciones de pensamiento puedan expresarse en competencias de acción, que sean competencias complejas en las que se mezcla el conocimiento abstracto con el experiencial, al que definimos como pensamiento tecnológico" (Aguerrondo, 2009: 9). El pensamiento tecnológico, por otra parte, exige enfocar los problemas desde su resolución (¿qué saberes necesitamos para resolver este problema?), lo que transciende los límites de las disciplinas científicas y académicas, porque los problemas nunca son disciplinares sino interdisciplinares. 
Es en este nuevo modelo de conocimiento y de pensamiento donde las competencias adquieren sentido porque "suponen precisamente un saber de otra índole, más allá del saber tradicional de la modernidad, un saber que integra el saber con el hacer" (Aguerrondo, 2009:7), concibiéndolas como desempeños del pensamiento complejo.

En la definición que recogíamos anteriormente de Tobón se destacan seis aspectos esenciales, que configuran el concepto de las competencias desde el enfoque complejo: procesos, complejidad, desempeño, idoneidad, metacognición y ética. Lo que significa que cada competencia exige un análisis de esos aspectos para orientar su enseñanza y aprendizaje y su evaluación, con las correspondientes implicaciones didácticas.

Pero esta ruptura epistemológica, instalada más en la sociedad que en la escuela y en la universidad, exige una urgente redefinición de los aprendizajes que deben lograr nuestros alumnos, para que todos los implicados (alumnado, profesorado, centros, comunidades educativas y sociales) se acostumbren, y adecuen su tarea, a que el producto de la educación no es formar personas que acumulan, y son capaces de reproducir, más o menos conocimientos, sino personas capaces de resolver problemas. Lo que significa que "dentro de las escuelas existe un potencial de ayuda a la comunidad, que puede ayudar a resolver problemas en su comunidad inmediata, problemas sociales o problemas individuales, concretos, reales, que podrían ser la materia desde donde la escuela tendría que poder trabajar para formar competencias complejas en sus alumnos. Una idea-fuerza de este tipo ayuda a producir cambios profundos porque redefine el trabajo de la escuela superando el compromiso de enseñar a pensar por el compromiso de enseñar a pensar-para-saber-hacer" (Aguerrondo, 2009: 10)

Desde este punto de vista, la incorporación de las competencias al curriculum puede contribuir de una forma más decidida y clara a la redefinición de los aprendizajes para que los cambios metodológicos que exigen estén plenamente justificados y adquieran pleno sentido para el profesorado. Esos métodos ya se están practicando desde hace mucho tiempo en nuestras escuelas (método de proyectos, aprendizaje basado en problemas, investigación-acción, etc.), pero por una minoría de profesores y en contra de los métodos tradicionales que imperan y sirven de base organizativa del curriculum (segmentación por áreas), de la evaluación (evaluación en función de los criterios de las áreas) y de la organización de los centros (dando prioridad absoluta a los departamentos, que son reflejo de la organización segmentada del curriculum por áreas).

\section{Las ideas fuerza del aprendizaje competente}

De las caracterizaciones de las competencias que ofrecen los organismos responsables de su implantación (OCDE, UE, MEC), y de la literatura especializada inducimos que para producir ese aprendizaje competente (complejo, de orden 
superior), y para avanzar en esta oportunidad de cambio y de mejora de la enseñanza, habría que considerar, al menos, tres ideas fuerza con sus correspondientes traslaciones didácticas: la significación del aprendizaje: las situaciones y los contextos; la utilización del conocimiento: la acción; y, la creación intersubjetiva de significados: la interacción.

\section{a) La significación del aprendizaje: las situaciones y los contextos}

La significación del aprendizaje es una tradición muy consolidada en la investigación que viene a concluir que si el aprendizaje no le resulta significativo al alumnado, es decir, no lo comprende, no es capaz de integrarlo en su estructura cognitiva, no es capaz de relacionarlo con lo que ya sabe, no es capaz de utilizarlo para resolver los problemas y las situaciones con las que se tiene que enfrentar en su vida, entonces sólo puede memorizar lo aprendido y con el tiempo lo olvida.

La traslación didáctica de esta idea fuerza del aprendizaje competente, es decir, lo que el profesorado puede hacer en la práctica docente para dar respuesta a esa idea se concreta en dos condiciones para la enseñanza y el aprendizaje: las situaciones y los contextos, porque se insiste en la necesidad de que el aprendizaje se produzca y se aplique en "situaciones contextualizadas" lo más significativas posible para el alumnado.

Se pone de manifiesto que el aprendizaje competente no se puede producir mediante tareas o actividades no situadas y descontextualizas, y, por tanto, carentes de significado personal o social ${ }^{8}$. Las situaciones a las que nos referimos se refieren a la vida cotidiana del alumnado, a su participación en la sociedad, a los derechos y deberes que supone la ciudadanía, e implican darle significado al aprendizaje. No es lo mismo aprender aisladamente el vocabulario sobre los medios de transporte y la gramática necesaria para construir las frases adecuadas para pedir información en una lengua extranjera (o propia), que saber pedir información sobre cualquier medio de transporte en una situación real o figurada. No es lo mismo aprender los números, las operaciones, las medidas y la geometría aislada y descontextualizadamente, que proponer "situaciones didácticas", como se sugiere desde la Teoría de las situaciones didácticas propugnada por Brousseau (1989, 1990, 1997).

Creemos que hay un cierto consenso en considerar tres contextos básicos: 1) individual o personal; 2) grupal o social, y 3) el entorno (físico, económico, político, cultural). Es cierto que el contexto "grupal o social" puede solaparse con el contexto "entorno", pues al fin y al cabo todo lo que rodea al individuo o a la

8 Es cierto que la construcción de los currículos basados en competencias admiten también las denominadas "situaciones de aprendizaje" debidas a la naturaleza del conocimiento, es decir, disciplinares, pero como complemento o ayuda, nunca como ejes del aprendizaje.

Rev. Esp. Doc. Cient., N. ${ }^{\circ}$ Monográfico, 46-74, 2012. ISSN: 0210-0614. doi: 10.3989/redc.2012.mono.977 
persona, incluida la familia, se podría considerar "entorno". El sentido de esta diferenciación, admitida de antemano su artificialidad, radica en crear un escenario de aprendizaje en torno al desarrollo de las relaciones grupales, intergrupales y sociales del alumnado, dejando para el otro contexto el desarrollo y comprensión de las relaciones del individuo o de la persona con el entorno físico, político, económico y cultural que le rodea, así como sus posibilidades de transformarlo.

Por otra parte, en el contexto "entorno" cabría establecer una secuenciación que se inicie en el ambiente más inmediato al alumnado (familia, colegio, calle, barrio considerados desde la perspectiva física, política, económica y cultural, no tanto desde las relaciones grupales y sociales) y fuese progresivamente hacia entornos mediatos, hasta llegar al contexto global (mundial, universal), en función del ciclo y la etapa correspondientes.

En relación con las situaciones el asunto es más complejo, si cabe. Así como parece conveniente establecer unos contextos de aplicación comunes a todas las competencias, no lo es tanto cuando nos referimos a las situaciones en las que el alumnado tendrá que aprender y poner de manifiesto su aprendizaje competencial.

Aun admitiendo la necesidad y la fuerza de los contextos y las situaciones para favorecer un aprendizaje más significativo, el problema no se resuelve tan fácilmente porque esos contextos son cambiantes, se modifican constantemente, interactúan entre ellos. ¿Eso significa que la escuela tiene que estar revisando constantemente esos contextos? ¿Eso es posible? Lo mismo sucede con las situaciones sobre las que puede actuar en esos contextos, ¿cuál es su grado de estabilidad? ¿Cómo interactúan entre sí las diferentes situaciones de cada contexto? ¿Cuándo podemos considerar que una situación ha cambiado y debe modificarse su versión didáctica? ¿La escuela tiene que estar revisando constantemente esas situaciones? ¿Eso es posible? Los currículos centrados en situaciones otorgaban una gran estabilidad a las situaciones sociales, grupales e individuales sobre los que se construían, ¿en el mundo actual se puede mantener esa estabilidad?

\section{b) La utilización del conocimiento: la acción}

Otra idea fuerza que nos interesa destacar en relación con el aprendizaje competencial es la de la "acción o aplicación del aprendizaje". Desde esta perspectiva no se puede decir que el alumnado ha aprendido algo si no es capaz de actuar en consecuencia, de aplicarlo o de utilizarlo en una situación contextualizada concreta. Un alumno no habrá aprendido la competencia matemática si no es capaz de utilizar los conocimientos matemáticos necesarios para resolver situaciones de su vida escolar o social. Lo que supone, que ante una situación concreta sabrá seleccionar el tipo de conocimiento o de saberes pertinentes (contenidos, habilidades prácticas y cognitivas, emociones, actitudes, valores, etc.) y aplicarlo para resolver esa situación. 
La necesidad de que el alumnado utilice el conocimiento sitúa el aprendizaje competencial en un nivel muy elevado (uso o aplicación), como ya hemos señalado, que supera el mero recuerdo. Sin embargo, para que el alumnado alcance este nivel de aprendizaje no sirve cualquier tipo de actuación, ni se trata tampoco de que el alumno esté constantemente haciendo cosas sumido en una especie de hiperactividad.

La acción es concebida sobre todo como solución de problemas, lo que implica la capacidad de relacionar recursos (conocimientos, procedimientos, habilidades, emociones, actitudes, valores, destrezas), y aplicarlos. Además, los problemas tienen que ser lo más reales posibles y relacionados con todos los contextos mencionados. Por último, tienen que ser de todo tipo: personales, emocionales, sociales, prácticos, tecnológicos, intelectuales, etcétera.

\section{c) Creación intersubjetiva de significados: la interacción}

Los procesos de aprendizaje que se derivan de las ideas-fuerza anteriores no resultarían tan poderosos si se concibieran individualmente. Quizás una de las exigencias más interesantes de la enseñanza y el aprendizaje de las competencias es su carácter interactivo. La interacción social (que en contextos educativos adopta comúnmente la forma de la interacción social entre iguales, mediada por el profesor) para la creación o construcción intersubjetiva de los significados es un enfoque del aprendizaje sustentado desde diversas teorías e investigadores. Piaget y la Escuela de Ginebra, Vigotsky (intersubjetividad) y los postvigotskianos (Edwards, Mercer, Forman, Cazden, Rogoff, Tudge, Wertsch, Wood...) y sus trabajos sobre la colaboración, y sus investigaciones acerca del conflicto cognitivo, la controversia y la influencia social; el aprendizaje vicario; Doise y Mugny y el conflicto sociocognitivo; el interaccionismo simbólico (Blumer, Mead, Cooley, Goffman); el aprendizaje dialógico o comunicativo (Freire, Habermas), por citar los más relevantes. Es cierto que cada enfoque y teoría citados aporta una visión particular de lo que significa y cómo se produce el aprendizaje basado en la interacción, y en ese sentido no todas las referencias son iguales, pero también es cierto, y lo que nos interesa resaltar aquí, es que rompen con lo que podríamos denominar una concepción tradicional del aprendizaje y, y sobre todo, con una tradición individualista del aprendizaje. Lo que no significa, en ningún caso, que se desconsidere el trabajo y el esfuerzo individual por y para aprender. Lo que se sugiere es que ese trabajo individual desempeña un papel diferente y forma parte de un proceso más complejo que implica la interacción con los demás. 


\section{Principios o criterios para la enseñanza basada en competencias}

La incursión generalizada de las competencias en el ámbito educativo desde la educación infantil hasta la universidad puede suponer un avance en la definición y el significado de los aprendizajes que el alumnado deberá adquirir. También es posible que ayuden a una construcción curricular mucho más adecuada para crear mejores condiciones de aprendizaje para todo el alumnado. Sin embargo, desde el punto de vista de la enseñanza el impacto puede resultar menos novedoso porque los pilares de la buena enseñanza, basada en competencias o no, ya están establecidos desde hace mucho tiempo.

Desde los planteamientos de una educación democrática de Dewey, pasando por la Escuela Nueva, la Escuela del Trabajo, Decroly, Montessori, Freinet, etc., hasta los planteamientos más actuales (cooperación y colaboración; aprendizaje basado en proyectos; aprendizaje basado en problemas; estudio de casos, etc.), se viene incidiendo en una enseñanza que logre lo que las competencias (y otras tecnologías para concebir y construir el curriculum) exigen: un aprendizaje significativo, contextualizado, situado, activo e interactivo. El problema es que estos planteamientos no se han generalizado en los sistemas educativos, especialmente en el español.

Podríamos describir algunas de estas metodologías, pero nos parece más adecuado insistir en algunos principios o criterios que cualquier enseñanza que pretenda lograr ese tipo de aprendizaje debería tener en cuenta. En ese sentido, el trabajo de Newmann y Wehlage (1993) y Newmann (2005) en torno a la idea de "enseñanza auténtica" parece muy clarificador.

Una enseñanza es auténtica si logra el aprendizaje que hemos descrito, o si logra que los alumnos: 1) construyan significado y produzcan conocimiento; 2) usen la investigación para construir significado, y 3) orienten su trabajo hacia la producción de discursos, productos y aplicaciones que tienen valor o significado más allá del éxito en la escuela. Para determinar si la enseñanza es auténtica establecen cinco criterios: 1) predomina el pensamiento de orden superior; 2) hay profundidad de pensamiento; 3) lo que se aprende conecta con el mundo real del alumnado; 4) favorece un nivel alto de conversación sustantiva, y 5) mantiene un apoyo social positivo al rendimiento del alumnado.

El predominio del pensamiento de orden superior, frente al pensamiento de orden inferior, conecta directamente con una de las exigencias del aprendizaje competencial. La escuela ha estado (y sigue estando) fomentando un pensamiento de bajo nivel (orden inferior) al pedir a los estudiantes que memoricen o reciten información factual o empleen reglas y algoritmos mediante rutinas repetitivas. Esta tradición, basada en la creencia de que el buen aprendizaje implica una gran acumulación de conocimiento, sin que el alumnado comprenda su significado, debe sustituirse por el fomento del pensamiento de orden superior que re- 
quiere del estudiante el manejo de información e ideas de forma que transforme su significado e implicaciones, lo que ocurre cuando combina hechos e ideas para sintetizar, generalizar, explicar, formular hipótesis, o llega a alguna conclusión o interpretación. El manejo de la información e ideas a través de esos procesos permite al alumnado resolver problemas y descubrir nuevos (para ellos) significados y comprensiones. Cuando los estudiantes se implican en desarrollar el pensamiento de orden superior se introduce un elemento de incertidumbre y los resultados de la enseñanza no son siempre predecibles, lo que choca con la enseñanza tradicional que ha convertido en un interés prioritario el establecimiento de resultados cerrados y previsibles para asegurar el control de lo que se enseña.

La profundidad de pensamiento se refiere al carácter sustantivo de las ideas y al nivel de comprensión que los alumnos demuestran al considerar ellos mismos esas ideas. El conocimiento es superficial cuando los conceptos nucleares y más significativos de un tópico o de una disciplina no se abordan convenientemente relacionados entre sí formando estructuras, más bien aparecen yuxtapuestos o simplemente como un listado inconexo. La superficialidad se debe en gran medida a las formas de organización curricular que favorecen la fragmentación del conocimiento (y en consecuencia su falta de significación) y a las estrategias de enseñanza que enfatizan más el tratamiento de grandes cantidades de información (igualmente fragmentada). Cualquier título universitario con una media de entre cuarenta y cincuenta asignaturas y de diez temas por asignatura le ofrece al alumnado el total del conocimiento de ese título en cuatrocientos o quinientos fragmentos que cada alumno tendrá que conectar si quiere comprender el significado de los conocimientos que ha recibido. Además, cada fragmento (o tema) se le presenta habitualmente como un listado de conceptos igualmente desconectados entre sí. El conocimiento es profundo cuando tiene que ver con las ideas centrales de un tópico o una disciplina. Al alumnado el conocimiento le resulta profundo cuando tienen claros los conceptos básicos de la disciplina o tópico de que se trate; puede desarrollar argumentos, resolver problemas y construir explicaciones en torno a esos conceptos; y, si trabaja con comprensiones relativamente complejas. La profundidad se produce, en parte, abordando pocos tópicos de forma sistemática y conectada.

La conexión con el mundo real tiene que ver con el valor que tenga lo aprendido para, y en, ese mundo real. En una clase con poco o ningún valor más allá del contexto escolar, las actividades son juzgadas importantes por su éxito únicamente en la escuela de forma inmediata o a largo plazo. Un aprendizaje gana en autenticidad en la medida en que hay más conexión con el contexto social más amplio o con el contexto profesional en el que trabajarán los alumnos. Dicho en otras palabras, la enseñanza conectará con el mundo real si los alumnos: 1) tratan con problemas del mundo real, o de su profesión, o 2) usan su experiencia personal como un contexto de aplicación del conocimiento. 
La conversación sustantiva se refiere al tipo de interacciones que se producen entre el alumnado, y entre éste y el profesorado. En las clases con poca o ninguna conversación sustantiva la interacción típica consiste en una lectura en la que el profesor se desvía muy poco de la información y de la serie de preguntas deliberadamente preplanificadas. La exposición del profesor es un discurso más yuxtapuesto que coherente. Los alumnos habitualmente dan respuestas muy cortas y hay poco o ningún seguimiento de las respuestas de los estudiantes. Por el contrario, los niveles altos de conversación sustantiva se identifican por cuatro características: 1) hay muchas interacciones acerca de un tema; 2) se produce una gran contribución de ideas en los intercambios, que no están completamente controlados; 3) la contribución es mejor cuando los alumnos explican o preguntan ellos mismo las cuestiones y cuando responden directamente a los comentarios de los interlocutores previos, y 4) el diálogo se construye coherentemente sobre las ideas de los participantes para promover la mejora de la comprensión colectiva de un tema.

El apoyo social al rendimiento del alumnado implica altas expectativas, respeto e inclusión de todos los estudiantes en el proceso de aprendizaje. El apoyo social es bajo cuando la conducta, los comentarios y las acciones del profesorado o del alumnado tienden a desanimar el esfuerzo, la participación o la predisposición para expresar sus propios puntos de vista. El apoyo social es alto en la clase cuando el profesorado transmite altas expectativas para todos los alumnos, para que todos los miembros de la clase puedan aprender habilidades y conocimientos importantes creando un clima de mutuo respeto entre todos los miembros de la clase que contribuya al rendimiento de todos. Este criterio tiene que ver con la capacidad de inclusión que sea capaz de lograr el profesorado.

A estos cuatro criterios creemos que es necesario añadir un quinto, que podríamos denominar "la organización social del aula" para abordar adecuadamente el desarrollo social y emocional del alumnado, que en los criterios anteriores queda muy desdibujado. Con ello nos referimos al reconocimiento del aula como el espacio óptimo para el desarrollo de las competencias sociales, entendidas como el conjunto de valores, habilidades, actitudes y conocimientos que permiten al alumnado aprender a convivir democráticamente. La organización del aula deberá concebirse con la expresa intención de influir en la construcción de las relaciones interpersonales. Se abordarán los procesos de toma de decisiones como un aprendizaje más del alumnado y se organizará su enseñanza con el mismo rigor que la de los demás aprendizajes. Un aula con una organización social deficiente se caracteriza por: no dedicar tiempo al aprendizaje de los procesos de toma de decisiones, organizativos y curriculares, que estarán centrados en el profesorado; una organización del espacio que no favorece las interacciones entre iguales y que focaliza la atención sobre el profesorado; y, los conflictos se resuelven jerárquicamente, decide el profesor. Por el contrario, un aula con una buena organización social se caracteriza por: dedicar el tiempo necesario al aprendizaje de los procesos de toma de decisiones, tanto organizativos (normas de 
convivencia y de funcionamiento de la clase) como curriculares (construcción del currículum), que estarán centrados en el conjunto de la clase; una organización del espacio especialmente diseñada para favorecer las interacciones entre iguales, que permite centrar la atención en función de las tareas que se vayan a desarrollar y, en cualquier caso, no focalizada en el profesor; y, un aula en la que los conflictos se resuelven democráticamente.

\section{El aprendizaje de las competencias informacionales y digitales: las dimensiones y ámbitos}

¿En qué medida lo que acabamos de exponer sobre la naturaleza y características del aprendizaje competente se proyecta con relación a la alfabetización informacional y digital? A continuación vamos a describir, de forma breve, y teniendo en cuenta los referentes y principios anteriores lo que serían las dimensiones implicadas en el aprendizaje, adquisición y desarrollo de las competencias informacionales y digitales que recogemos en la figura 1. Como puede verse identificamos cinco grandes dimensiones (Area y Pessoa, 2012) que son las siguientes: dimensión cognitiva: dimensión instrumental, dimensión cognitiva, dimensión sociocomunicacional, dimensión axiológica y dimensión emocional (figura 1).

Estas dimensiones se proyectan o se traducen en tres ámbitos de aprendizaje que debieran ser cultivados y trabajados en todo proyecto educativo de alfabetización en las competencias informacionales y digitales a lo largo de la vida de un sujeto sea desde la educación infantil hasta la educación superior (véase figura 2). Nos referimos a los ámbitos de:

- aprender a buscar, localizar y comprender la información empleando todos los tipos de recursos y herramientas (libros, ordenadores, Internet, tabletas, etc.);

- aprender a expresarse mediante distintos tipos de lenguajes, formas simbólicas y tecnologías y, en consecuencia, saber difundir públicamente las ideas propias sea mediante presentaciones multimedia, blogs, wikis o cualquier otro recursos digital, y

- aprender a comunicarse e interaccionar socialmente con otras personas a través de los recursos de la red (email, foros, redes sociales, videoconferencias, etc.).

En consecuencia, cualquier programa de formación ALFIN o de alfabetización digital tendría que ser planificado, desarrollado y evaluado en función de estos tres ámbitos para aprender a realizar un uso culto e inteligente de la información. Es decir, sea en el contexto escolar de la educación básica (Primaria y Secundaria), sea en el nivel universitario, sea en el ámbito de la formación de personas adultas, sea desde las bibliotecas, o en la formación ocupacional..., el 
FIGURA 1

\section{Dimensiones de la competencia informacional y digital}
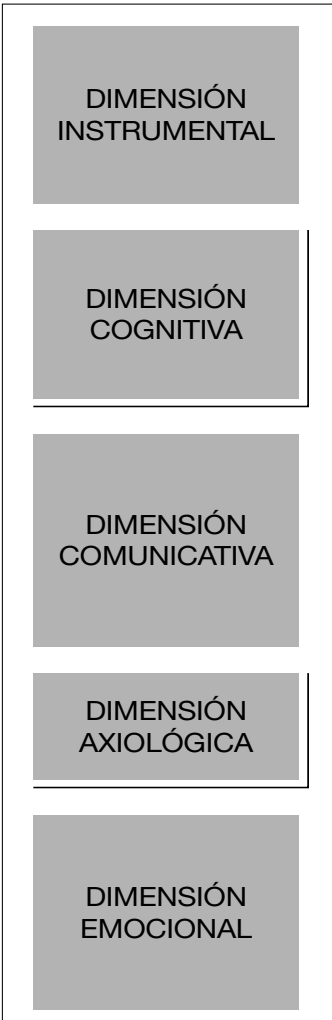

Saber acceder y buscar información en distintos tipos de medios, tecnologías, bases de datos o bibliotecas.

Saber transformar la información en conocimiento (habilidades de selección, análisis, comparación, aplicación, etc.).

Saber expresarse y comunicarse a través de múltiples lenguajes y medios tecnológicos.

Saber usar ética y democráticamente la información.

Saber disfrutar y controlar las emociones de forma equilibrada con las TIC desarrollando conductas socialmente positivas.
Adquirir las habilidades instrumentales para emplear cualquier tipo de medio (impresos, audiovisuales, digitales) y uso de los recursos de búsqueda.

Dominar los conceptos y estrategias para plantear problemas, analizar e interpretar con significado la información.

Tener las habilidades y conocimientos para crear documentos textuales, hipertextuales, audiovisuales, y multimedia, así como saber interaccionar con otros en redes digitales.

Asumir e interiorizar actitudes y valores éticos sobre la información y la comunicación.

Adquirir y desarrollar la capacidad de control de emociones negativas y de adicción hacia las TIC y de desarrollo de la empatía a través espacios virtuales.

\section{FIGURA 2}

\section{Ámbitos de aprendizaje de las competencias informacionales y digitales}

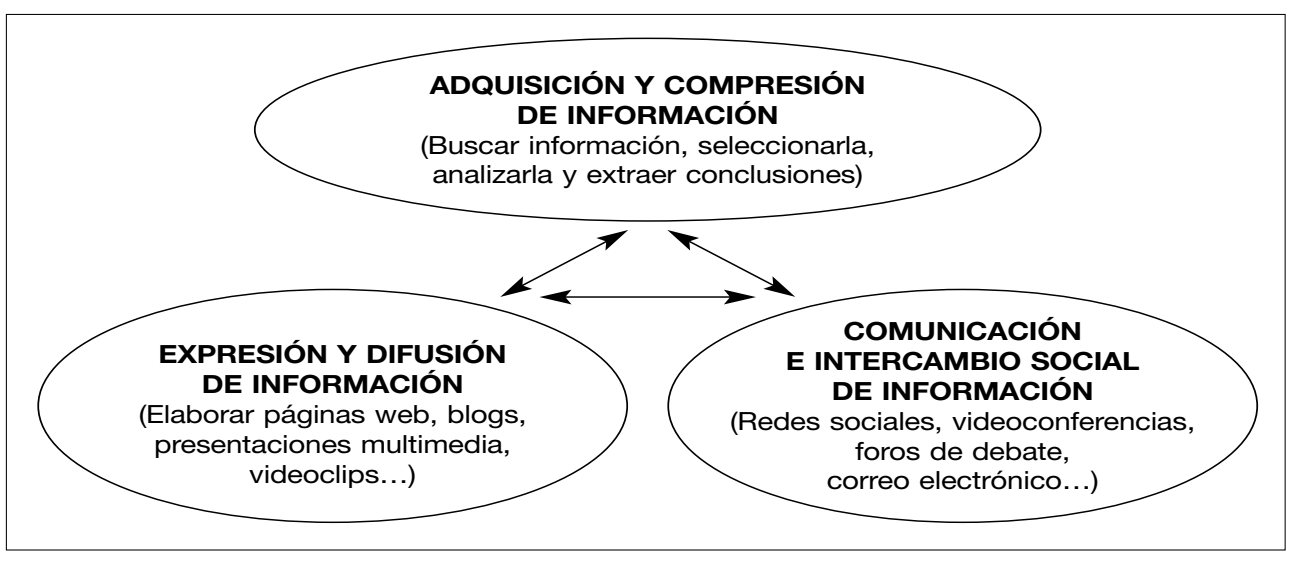


diseño de los programas formativos tendrían que elaborarse potenciando estos tres ámbitos de forma simultánea de modo que los sujetos aprendan a buscar información y analizarla, aprendan a producir, expresar y difundir información, y aprendan a comunicarla socialmente.

En esos programas formativos tendrían que planificarse actividades y tareas de aprendizaje que fueran un continuum o un ciclo reiterado caracterizado por una metodología de enseñanza destinada a que sea cada individuo quien construya su propio conocimiento competente que sintetizamos en la tabla IV. Este proceso iría encaminado a que cada sujeto sea capaz de interiorizar cinco pasos o fases que van desde la pregunta inicial de qué información o dato se necesita ante una determinada situación problemática hasta la difusión pública del conocimiento construido personalmente.

\section{TABLA IV}

Fases del proceso de elaboración y desarrollo del aprendizaje competente en información

\begin{tabular}{l|l}
\hline 1. Detectar la necesidad de información. & $\begin{array}{l}\text { Ante una situación problemática ¿qué infor- } \\
\text { mación o datos son necesarios? }\end{array}$ \\
\hline 2. Acceder a la información. & $\begin{array}{l}\text { ¿Dónde está la información? ¿Cómo se acce- } \\
\text { de a ella? }\end{array}$ \\
\hline $\begin{array}{l}\text { 3. Analizar, seleccionar e interpretar la in- } \\
\text { formación. }\end{array}$ & $\begin{array}{l}\text { ¿Es útil y pertinente la información encon- } \\
\text { trada? ¿Qué aporta de interés para resolver } \\
\text { las necesidades planteadas? ¿Qué significado } \\
\text { y valor tiene? }\end{array}$ \\
\hline $\begin{array}{l}\text { 4. Reelaborar y representar el conocimiento. } \\
\text { ¿Qué conclusiones se puede extraer? ¿Cómo } \\
\text { representar lo aprendido? ¿Con qué formato } \\
\text { y/o lenguaje se pueden expresar? }\end{array}$ \\
\hline $\begin{array}{l}\text { 5. Difundir y compartir el conocimiento a a } \\
\text { través de múltiples fuentes y tecnologías. }\end{array}$ & $\begin{array}{l}\text { ¿Dónde y con qué medios y recursos se pue- } \\
\text { de publicar y difundir el conocimiento ela- } \\
\text { borado? ¿Cómo interaccionar e intercambiar } \\
\text { ese nuevo conocimiento o información con } \\
\text { otras personas? }\end{array}$ \\
\hline
\end{tabular}

\section{Las competencias informacionales $y$ digitales son indispensables para navegar por los territorios de la cultura líquida}

La información como ya expresamos en otro trabajo (Area y Pessoa, 2012) es líquida y, en consecuencia, los ciudadanos del siglo xxi tenemos que adquirir y desarrollar competencias con relación a ser capaz de manejarse o navegar exitosamente entre los territorios actuales del conocimiento y de la cultura que 
adopta formas digitales 9 . Sin las herramientas y capacidades mentales adecuadas estaremos indefensos para enfrentarnos a las variadas formas de representación de la información, perdidos ante el enorme universo informacional que crece constantemente y limitados como sujetos que interaccionan y se comunican socialmente a través de redes digitales.

La información digitalizada y los entornos de comunicación virtuales representan un nuevo ecosistema o hábitat para la vida cotidiana del ciudadano del siglo Xxi. En este nuevo medioambiente sobreviven y crecen aquellos individuos o colectivos sociales que dispongan de las competencias para producir, difundir y consumir información de forma rápida, eficaz y eficiente, es decir, de forma exitosa para desenvolverse como sujeto socializado. Y para ello, es fundamental e imprescindible saber transformar la información en conocimiento, disponer de las habilidades y capacidades para utilizar de forma eficiente los recursos y herramientas tanto de búsqueda de información como de producción y difusión de la misma, así como para comunicarla y compartirla socialmente a través de las distintas herramientas y entornos digitales. En definitiva, es imprescindible la alfabetización informacional y digital de la ciudadanía del siglo xxI.

Como sugiere Morin (2001) la educación siempre ha tendido a enseñar certezas, saberes supuestamente cerrados, definitivos y poco cuestionables. Sin embargo, el tiempo actual se caracteriza precisamente por la sensación de que el conocimiento es efímero, cambiante y relativo. Morin, por ello, reivindica, como uno de los sietes saberes básicos, la necesidad de reorientar el sentido último de la educación hacia la formación de sujetos que sepan vivir y afrontar la incertidumbre inevitable del conocimiento. En palabras del propio autor: "El problema universal para todo ciudadano del nuevo milenio (es) ¿cómo lograr acceder a la información sobre el mundo y cómo lograr la posibilidad de articularla y organizarla? ¿Cómo percibir y concebir el contexto, lo global, lo multidimensional y lo complejo? (Morin. 2001: 43)

Aquí radica la idea central sobre la que pivota la propuesta defendida en este documento: la formación no puede consistir en la mera presentación o exposición del conocimiento y la información como algo definido y sin fisuras transmitido por fuentes de autoridad (un profesor o un libro) irrefutables. En un mundo complejo y en permanente mutación sobrevivirán con mayores posibilidades de éxito aquellos que manifiesten una actitud favorable hacia la adaptación a los cambios a la vez que posean los conocimientos y destrezas necesarias para resolver situaciones problemáticas.

9 En las evaluaciones internacionales comparando las competencias entre estudiantes, el último informe PISA ha incorporado el análisis del dominio de la competencia relativa a la lectura de textos digitales (OCDE, 2011). Dicho informe indica que España todavía se encuentra lejos de los primeros puestos. El promedio de puntuación en esta competencia de lectura digital de los estudiantes españoles es 475 puntos, es decir, está por debajo de la media del conjunto de países de la OCDE que fue de 499 puntos. 
Otro de los ejes o saberes fundamentales de la educación del futuro es educar para la comprensión. Como ya indicamos anteriormente, el acceso a muchos datos e informaciones no garantiza necesariamente el conocimiento e interpretación cognitiva de los mismos. La comprensión es un acto intelectual complejo en el que intervienen numerosas habilidades cognitivas (discriminar, analizar, clasificar, etc.) donde el individuo integra la nueva información en estructuras de pensamiento que ya poseía, creándose de este modo una nueva idea o conocimiento. Psicólogos educativos, como Ausubel, denominaron a este proceso como aprendizaje significativo, es decir, aprender algo nuevo otorgándole significado o comprensión. De este modo el aprendizaje significativo en los estudiantes se contrapone al aprendizaje memorístico o repetitivo de datos, conceptos o procedimientos. La condición inicial, pero no suficiente, para la comprensión, o si se prefiere para la construcción del conocimiento, es el acceso a la información. Sin datos, sin conocimiento previo, no puede elaborarse significado.

Si es el propio alumnado el que debe "construir/descubrir" el conocimiento entonces la labor o función pedagógica del docente no solo debe consistir en seleccionar y mostrar el contenido científico a adquirir, sino también planificar las tareas, las actividades y los recursos necesarios (bibliografía, documentos, materiales, sitios web...) para que sean los propios estudiantes quienes autónomamente busquen, analicen y construyan el contenido o conocimiento de estudio de la materia. En definitiva, un proceso de aprendizaje constructivo del conocimiento por parte de los estudiantes será facilitado si se articulan y confluyen, entre otros, factores como (Area, 2007).

- La planificación e implementación de un conjunto de actividades o tareas de aprendizaje variadas organizadas por el profesor que vayan más allá de la mera repetición de lo que dicen los apuntes o los manuales y requiera al alumnado un esfuerzo intelectual de alto nivel (análisis, clasificación, selección, síntesis, transferencia, etc.). Ello implica planificar y desarrollar un modelo didáctico basado en un proceso de aprendizaje activo del estudiante, es decir, un modelo que facilite el "aprender haciendo" más que el "aprender recibiendo".

- La disponibilidad de recursos de información, tecnológicos y materiales didácticos de naturaleza diversa (libros, aulas virtuales, blogs, dossieres bibliográficos, páginas web, audiovisuales, etc.) al alcance del alumnado para que éste pueda realizar las actividades de aprendizaje correspondientes, para que busque y utilice la información disponible en bibliotecas, bases de datos o repositorios digitales...

- El desarrollo en los usuarios de competencias y habilidades para saber buscar, seleccionar, analizar y reelaborar información a través de múltiples fuentes. Si el alumnado no posee estos conocimientos y destrezas para acceder de forma autónoma a la información o si la mayoría no sabe cómo hacerlo es evidente que la única solución es "copiar y pegar" de unos tra- 
bajos a otros. A todas luces esta práctica es rechazable pedagógica, científica y éticamente. Los estudiantes se convierten en meros reproductores o copiadores de información, pero no hay construcción de conocimiento.

\section{Concluyendo: algunas ideas básicas para el desarrollo futuro del ALFIN}

Como ya indicamos el ecosistema informacional es inmenso, casi inabarcable y no existen cartografías o mapas de navegación para recorrerlo. Las diferencias culturales entre unos individuos y otros están empezando a producirse con relación al grado de dominio de las competencias adecuadas para sobrevivir y navegar exitosamente en los vastos territorios de la información. La alfabetización ante las nuevas formas culturales que acompañan a la sociedad digital es una de las necesidades de primer orden en la ciudadanía actual y previsiblemente de las próximas décadas.

En ocasiones, en la práctica desarrollada en muchos de los programas y cursos de alfabetización informacional desarrollados desde bibliotecas o centros de documentación se ha focalizado en la enseñanza de los procedimientos de búsqueda de información en bases de datos bibliográficas. Es una formación necesaria, pero insuficiente. Se enfatiza la adquisición de competencias de usuarios que buscan y leen información, pero se obvia el desarrollo de las habilidades o capacidades expresivas de los sujetos para que sepan generar y comunicar información. Es decir, el eje formativo se focaliza en el desarrollo de los aprendizajes instrumentales de búsqueda de información, desconsiderando o no teniendo en cuenta el desarrollo de dimensiones cognitivas más complejas (como es el análisis, la discriminación o la comparación), o de dimensiones vinculadas con la interacción comunicativa en entornos virtuales, o con la producción, recreación y difusión de la información a través de múltiples formatos y lenguajes expresivos.

Desde nuestro punto de vista estos enfoques y prácticas de la alfabetización informacional debieran ampliar sus referentes teóricos incorporando nuevos ámbitos y metas educativas como los referidos anteriormente (es decir, no sólo saber buscar información digitalizada, sino también saber producirla y difundirla socialmente, así como incorporar la dimensión axiológica y emocional del aprendizaje) así como plantear esta alfabetización como un proceso de aprendizaje continuo a lo largo de toda la vida para toda la población desde el ámbito de educación infantil a la educación superior y permanente.

En síntesis, desde nuestro punto de vista, el futuro de ALFIN debiera pasar por asumir algunas ideas o criterios clave como los siguientes:

- Incorporar la formación en las competencias no sólo de acceso a la información, sino también de producción de información a través de distintos 
lenguajes expresivos (textual, hipertextual, icónico y audiovisual) y de hacerla pública o difundirla en los distintos espacios sociales de comunicación (redes sociales, web 2.0, repositorios...).

- Desarrollar ALFIN en todos los niveles y ámbitos educativos: Educación Primaria, Secundaria, Educación de Adultos, Educación Superior.

- Plantear ALFIN no sólo como aprendizaje en contextos de enseñanza formal, sino también como un proceso de autoaprendizaje en contextos formativos no formales tales como son la comunicación e intercambio de información en redes sociales, las experiencias personales de navegación a través de Internet y los hallazgos incidentales de información valiosa en bases de datos y repositorios digitales de diversa naturaleza.

- Planificar y desarrollar ALFIN desde una perspectiva multidimensional que cultive y desarrolle en los sujetos no sólo el aprendizaje instrumental, sino también el cognitivo, el sociocomunicacional, el axiológico y el emocional con relación a la información y el conocimiento.

\section{Bibliografía}

Aguaded, I. (2001). La educación en medios de comunicación: panorama y perspectivas. Murcia: KR, 2001.

Aguaded, I. (2011). La educación mediática, un movimiento internacional imparable. La ONU, Europa y España apuestan por la educomunicación. Comunicar: Revista científica iberoamericana de comunicación y educación, 37, 7-9.

Aguerrondo, I. (2009). Conocimiento complejo y competencias educativas, IBE Working Papers on Curriculum Issues, n. ${ }^{\circ}$ 8, UNESCO, Ginebra, Suiza. Disponible en: http://www.ibe.unesco.org/fileadmin/user_upload/Publications/Working_Papers/kno wledge_compet_ibewpci_8.pdf [consultado el 26/3/2012].

Aparici, R. (coord.) (1996). La revolución de los medios audiovisuales. Educación y Nuevas Tecnologias. Madrid: La Torre.

Aparici, R. (2005). Medios de comunicación y educación. Revista de educación, 338, 85-100.

Area, M. (2005). La educación en el laberinto tecnológico. De la escritura a las máquinas digitales. Barcelona: Octaedro.

Area, M. (2007). Adquisición de competencias en información. Una materia necesaria en la formación universitaria. Documento inédito. Documento marco de REBIUN para la CRUE. Disponible en: www.rebiun.org/export/docReb/Adquisiciondecompetencias.doc [consultado el 19/3/2012].

Area, M. (2010). Tecnologías digitales, multialfabetización y bibliotecas en la escuela del siglo xxi. Boletín de la Asociación Andaluza de Bibliotecarios, n. ${ }^{\circ}$ 98-99, enero-junio, 39-52. Disponible en: http://www.aab.es/aab/images/stories/Boletin/98_99/2.pdf [consultado el 9/1/2012].

Area, M. Gros, B.; Marzal, M. A. (2008). Alfabetizaciones y Tecnologias de la Información y Comunicación. Madrid: Síntesis. 
Area, M.; Pessoa, T. (2012). De lo sólido a lo líquido: Las nuevas alfabetizaciones ante los cambios culturales de la Web 2.0. Comunicar, XIX, 38, 13-20. Disponible en: http://dx.doi.org/10.3916/C38-2011-02-01 [consultado el 9/3/2012].

Bauman, Z. (2006). Modernidad líquida. Buenos Aires: Fondo de Cultura Económica.

Bautista García-Vera, A. (2007). Alfabetización tecnológica multimodal e intercultural Revista de Educacion, 343, mayo-agosto, 589-600.

Bawden, D. (2002). Revisión de los conceptos de alfabetización informacional y alfabetización digital. Anales de documentación, n. ${ }^{\circ}$ 5, 361-408. Disponible en: http://revistas.um.es/analesdoc/article/viewFile/2261/2251 [consultado el 19/3/2010].

Benito-Ruiz, E. (2009). Infoxication 2.0. En Thomas, M. (ed.) Handbook of Research on Web 2.0 and Second Handbook of Research on Web 2.0 and Second Language Learning. Pennsylvania: IGO-InfoSci, p. 60-79

Brousseau, G. (1989). Fundamentos de didáctica de la matemática. Zaragoza: Universidad de Zaragoza.

Brousseau, G. (1990). Obstacles épistemologiques, conflicts socio-cognitifs et ingénierie didactique. En N. Bednarz y C. Garnier (eds.) Construction des savoirs. Québec: Agenced'ARC.

Brousseau, G. (1997). The theory of didactic situations. Dordrecht: Kluwer A. P.

Bryant, Antony. 2007. Liquid Modernity, Complexity and Turbulence. Theory, Culture and Society, 24: 1, 127-135.

Burch, S. (2005). Sociedad de la información y Sociedad del conocimiento. En Ambrossi, A.; Peugeot, V.; Pimienta, D. (2005). Palabras en juego: Enfoques Multiculturales sobre las Sociedades de la Información. París: CF. Editions.

Carr, N. (2010). ¿Qué está haciendo Internet con nuestras mentes? Superficiales. Madrid: Taurus.

Coll, C. (2005). Lectura y alfabetismo en la sociedad de la información. UOC Papers, n. ${ }^{\circ} 1$. Disponible en: http://www.uoc.edu/uocpapers/1/dt/esp/coll.pdf [consultado el 27/11/2011]

Comisión Europea. Grupo de Trabajo B. (2004). Competencias clave para un aprendizaje a lo largo de la vida. Un marco de referencia europeo. Documento de trabajo, noviembre.

Cope, B.; Kalantzis, M. (2010). Multialfabetización: nuevas alfabetizaciones, nuevas formas de aprendizaje. Boletín de la Asociación Andaluza de Bibliotecarios, n. ${ }^{\circ}$ 98-99, enero-junio 2010, 53-91. Disponible en: http://www.aab.es/aab/images/stories/Boletin/98_99/3.pdf [consultado el 9/1/2012].

Dini, P.; Iqani, M.; Mansell, R. (2011) The (im)possibility of interdisciplinarity: lessons from constructing a theoretical framework for digital ecosystems. Culture, theory and critique, 52 (1), 3-27. Disponible en: http://eprints.lse.ac.uk/29152/ [consultado el $12 / 12 / 2011]$.

Elmore, E. (1990). La reestructuración de las escuelas, la siguiente generación de la reforma educativa. México: Fondo de Cultura Económica. 
Ferrés, J.; Piscitelli (2012). La competencia mediática: propuesta articulada de dimensiones e indicadores. Comunicar, XIX, 38, 75-82. Disponible en: http://dx.doi.org/10.3916/ C38-2011-02-08 [consultado el 12/1/2012].

Frau-Meigs, D.; Torrent, J. (2009). Políticas de educación en medios: Hacia una propuesta global. Comunicar, XVI, 32. Disponible en: http://dx.doi.org/10.3916/c32-2009-01001 [consultado el 26/11/2011].

Gutiérrez, A. (2003). Alfabetización digital. Algo más que ratones y teclas. Barcelona: Gedisa.

Gutiérrez, A. (2010). Creación multimedia y alfabetización en la era digital. En Aparici, R. (coord.). Educomunicación: más allá del 2.0. Barcelona: Gedisa.

Kaplun, M. (1998). Una pedagogía de la comunicación. Madrid: La Torre.

Kellner, D. M. (2004). Revolución tecnológica, alfabetismos múltiples y la reestructuración de la educación. En Snyder, I. Alfabetismos digitales. Archidona: Ediciones Aljibe.

Kress, G. (2005). El alfabetismo en la era de los nuevos medios de comunicación. Málaga: Aljibe.

Lankshear, C.; Knobel, M. (2009). Nuevos alfabetismos. Su práctica cotidiana y el aprendizaje en el aula. Madrid: Morata.

Maldonado, C.E. (2003). Marco teórico del trabajo en ciencias de la complejidad y siete tesis sobre la complejidad. Revista Colombiana de Filosofía de la Ciencia, vol. 4, n. ${ }^{\circ}$ 8-9.

Marzal, M. A. (2009). Evolución conceptual de la alfabetización en información a partir de la alfabetización múltiple en su perspectiva educativa y bibliotecaria. Investigación bibliotecológica, v. 23, n. ${ }^{\circ} 47,129-160$. Disponible en: http://www.ejournal.unam.mx/ ibi/vol23-47/IBI002304706.pdf [consultado el 28/11/2011].

Marzal, M. A. (2010). La evaluación de los programas de alfabetización en información en la educación superior: estrategias e instrumentos. Revista de Universidad y Sociedad del Conocimiento, RUSC, v. 7, n. ${ }^{\circ}$ 2, Disponible en: http://rusc.uoc.edu/ojs/index. $\mathrm{php} / \mathrm{rusc} /$ article/view/v7n2-marzal/v7n2-marzal [consultado el 2/12/2011].

Marzano, R. J. (1998). A theory-based meta-analysis of research on instruction. Aurora, Colorado: McREL. Disponible en: www.mcrel.org/PDF/Instructioren/5982RR InstructionMeta_Analysis.pdf [consultado el 2/9/2011].

Marzano, R. J. (2000). Designing a new taxonomy of educational objectives. Thousand Oaks, California: Corwin Press.

Masterman, L. (1993): La enseñanza de los medios de comunicación. Madrid: La Torre.

Mayos, G.; Brey, A. (eds.) (2011). La sociedad de la ignorancia. Barcelona: Península.

Merrill, M. D. (1971): «Necessary Psychological Condition for Defining Instructional Outcomes", Educational Technology, agosto 1971: 34-39.

Merrill, M. D. (1973). Content and Instructional analysis for cognitive transfer task, $A V$ Communication Review, 21 (1), 109-125.

Merrill, M. D. (1977). Content analysis via Concept Elaboration Theory. Journal of Instructional Development, 1: 10-13.

Monereo, C. (coord.) (2005). Internet y competencias básicas. Aprender a colaborar, a comunicarse, a participar, a aprender. Barcelona: Graó. 
Morin, E. (2001). Los siete saberes necesarios para la educación del futuro. Barcelona: Paidós.

Newmann, F.M. (2005). Authentic Pedagogy: Rationale, Research and Implications for Teacher Education. Paper Presented to Carnegie Foundation sponsored Teachers for a New Era conference, nov. 14-15, Chicago.

Newmann. F. M.; Wehlage, G. G. (1993). Five Standards of Authentic Instruction. Educational Leadership, April 1993, v. 50, n. ${ }^{\circ}$ 7: 8-12.

OCDE (2002). Definition and selection of competencies (DeSeCo): theoretical and conceptual foundations. Strategy Paper.

OCDE (2011). PISA 2009 Results: Students on Line: Digital Technologies and Performance (Volume VI). Disponible en: http://dx.doi.org/10.1787/9789264112995-en. Versión en español en http://www.educacion.gob.es/dctm/ievaluacion/internacional/informe-espanol-pisa-era-2009.pdf?documentId=0901e72b80d24b47 [consultado el 6/10/2011].

Pinto, M., Uribe, A., Gómez, R.; Cordón, J.A. (2011). La producción científica internacional sobre competencias informacionales e informáticas: tendencias e interrelaciones. Información, cultura y sociedad, n. ${ }^{\circ} 25,29-62$.

Romiszowski, A. J. (1981). Designing Instructional Systems: Decision-Making in course planning and curriculum design, London: Kogan Page.

Tobón, S. (2001). Aprender a emprender. Un enfoque curricular. Medellín: Funorie.

Tobón, S. (2002). Modelo pedagógico basado en competencias. Medellín: Corporación Lasallista.

Tobón, S. (2005). Formación basada en competencias. Pensamiento complejo, diseño curricular y didáctica. Bogotá: ECOE Ediciones.

Tobón, S. (2006a). Las competencias en la educación superior. Politicas de calidad. Bogotá: ECOE.

Tobón, S. (2006b). El diseño del plan docente en información y documentación acorde con el espacio europeo de educación superior. Madrid: Editorial Universidad Complutense de Madrid.

Tobón, S. (2007). Gestión curricular y ciclos propedéuticos. Bogotá: ECOE.

Urbano, C. (2009) Algunas reflexiones otoñales a propósito de la 'infoxicación'. Notas ThinkEPI, 12 de octubre. Disponible en: http://www.thinkepi.net/tag/infoxicacion [consultado el 2/1/2012].

Westera, W. (2001). Competences in education: a confusion of tongues. Journal of Curriculum Studies, 33, 75-88. 